\title{
Pay gap growing between family doctors, other specialists
}

Cite as: CMAJ 2017 October 16;189:E1300. doi: 10.1503/cmaj.109-5508

Posted on cmajnews.com on September 28, 2017.

C anada has more doctors than ever, with growth in the physician supply outpacing population increases for the 10th year in a row, according to the Canadian Institute for Health Information (CIHI). However, growth in the number of doctors is slowing, as are increases in payments to physicians for clinical services, with widening disparities between specialties.

"Although the supply of physicians and the total payments for their services continue to grow, over the last few years we've observed a reduction in the strength of that growth compared with earlier periods," said Geoff Ballinger, manager of physician information at $\mathrm{ClHI}$.

Canada's medical workforce has grown nearly three times as fast as the population since 2012, CIHI reports in Physicians in Canada, 2016.

Last year, there were 84063 doctors in Canada, or 230 per 100000 population the highest proportion ever. However, this represents an increase of $2.3 \%$ over 2015, the lowest growth rate in five years.

Despite the slow-down, $\mathrm{ClHI}$ anticipates physician numbers in Canada will continue to increase for the next several years, based on the number of degrees being awarded by Canadian universities.

Canada also gained 58 more doctors than it lost to international migration in 2016. One-quarter of Canada's physicians earned their medical degree abroad.

\section{Pay increases shrinking}

Growth in total clinical payments to physicians has also dropped off in the last few years. Last year, total payments to physicians increased $3.4 \%$ to $\$ 25.7$ billion. That's almost half the average annual growth of the past decade (6.2\%).

The average gross clinical payment per physician increased less than $1 \%$ over to

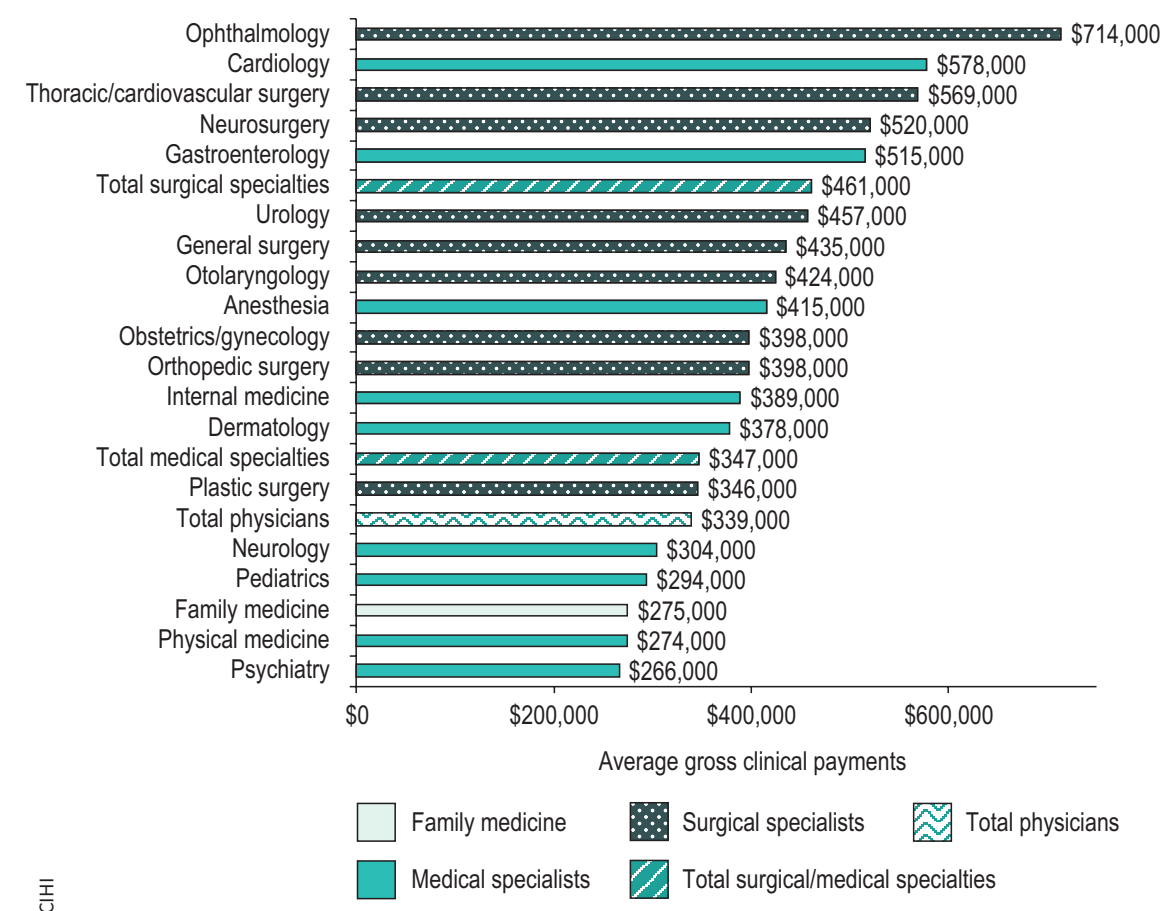

Average clinical payments to family doctors shrunk last year, while payments to other specialists increased.

$\$ 339000$. However, a closer look by specialty shows that some doctors fared better than others. Average gross clinical payments to family doctors actually decreased by nearly $1 \%$ to $\$ 275000$ in $2015 / 16$, while payments to other specialists increased by as much as $1.8 \%$, with surgical specialists receiving an average $\$ 461000$. On average, family doctors received almost half as much per service as other specialists.

Changes in payment patterns may affect the growing number of women and new graduates in the physician workforce. Across all jurisdictions, women represented a larger proportion of family doctors than other specialists in 2016. Since 2016, the number of female physicians increased by $21 \%$, while the number of male physicians increased $6.1 \%$. The proportion of recent graduates also rose from $16.2 \%$ in 2012 to $20 \%$ in 2016 , and more than half of physicians under 40 were female.

Notably, younger physicians and female physicians were more likely to receive most of their payment through alternative payment plans, as were family doctors. These plans were introduced by governments to discourage the episodic care associated with fee-for-service payments, as this payment model incentivized seeing as many patients as possible.

However, $\mathrm{ClHI}$ data shows the shift toward alternative payment plans has plateaued, with fee-for-service payments accounting for $70 \%-73 \%$ of total clinical payments since 2008 .

Lauren Vogel, CMAJ 